\title{
Transformerless Photo Voltaic Inverter Topologies for Low Power Domestic Applications
}

\author{
G. Janardhan, Dr.N.N.V. Surendra Babu \\ CVR College of Engineering/EEE Department, Hyderabad, India \\ Email: g.janardhan@cvr.ac.in \\ CVR College of Engineering/ EEE Department, Hyderabad, India \\ Email: surendrababu@cvr.ac.in
}

\begin{abstract}
In the last two decades there is significant growth in solar power due to the developments in photovoltaic (PV) and power semi conductor technologies. Traditionally a photovoltaic system consists of either a line frequency transformer on ac side or a high frequency transformer on de side to provide galvanic isolation between PV panels and grid. By removing transformer from PV system, the size of the system can be reduced significantly and efficiency can be improved. However, with the presence of parasitic capacitance between PV and ground, a variable common mode voltage appears in the system. This results in increase of leakage current and distortion in grid current. This paper presents a study on various inverter topologies that are used in harvesting the solar power. Further, a simulation study is carried out on a single phase $\mathrm{H} 4$ topology to assess the performance using bipolar and unipolar pulse width modulation (PWM) techniques. The simulation study is carried out in MATLAB SIMULINK and results are presented.
\end{abstract}

Key words: Transformerless Inverter, parasitic capacitance, Variable common mode voltage, leakage current, Bipolar PWM and Unipolar PWM.

\section{INTRODUCTION}

Renewable energy, especially solar energy became popular in the last two decades due to shortage of fossil fuels and environmental concerns. On the other hand, it is also due to significant advances in photo voltaic conversion technology and reduction in cost-per-watt on a large scale production. Solar power has grown consistently by 20 to $25 \%$ per annum over the last two decades. Various types of power electronic topologies are developed in literature to pump solar power into the grid [2].

Grid connected PV inverters are mainly classified into four types: (i) Central Inverter (ii) String Inverter (iii) Module integrated Inverter or Micro Inverter (iv) Multi String Inerter [2].

Central Inverter: Central inverter is used for large power plants [3]. PV modules are arranged in parallel stings and connected to a central inverter shown in Fig.1. Initially, line commutated thyristor based inverters were used in the topology. However, IGBT devices replaced thyristors gradually due to high efficiency and low cost [5]. This topology has following dis advantages :

- High voltage DC cables are needed between PV panels and inverter

- Power loss increases due to common MPPT

- Power loss due to module mismatch

- Losses in string diodes

- Less reliability due to single inverter

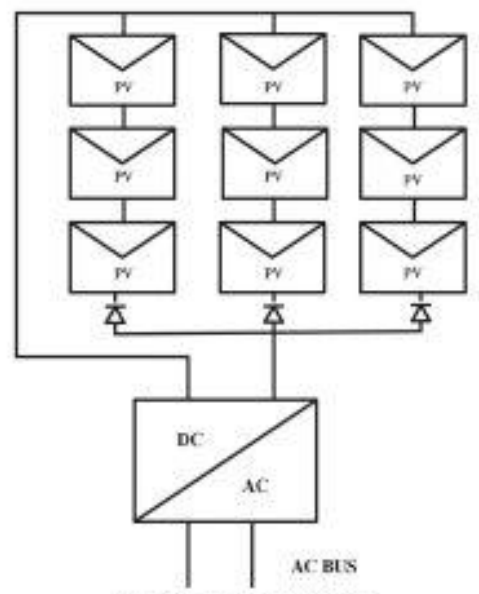

Figure 1, Central Inverter

String Inverter: String inverters are developed in 1995. The PV panels are connected in series to form arrays. Each array is connected to a separate inverter as shown in Fig. 2 . If the string voltage is sufficiently high, there is no necessity to boost the voltage. Otherwise, a DC-DC converter or a line frequency transformer is required to boost the output voltage. This additional component decreases the efficiency.

Module Integrated Inverter: In this topology, each PVmodule connected to a separate inverter which is connectedto the grid as shown in Fig.3 [2]. This kind of connectionensures maximum power from $\mathrm{PV}$ modules due to individual Maximum Power Point Tracking.

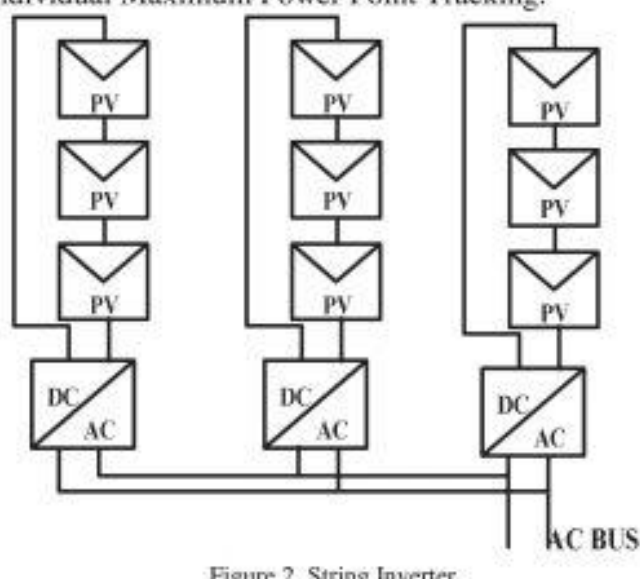

Due to its modular structure further expansion of the plant is easier [2]. The topology has drawbacks (i) Reduction in 
overall efficiency due to higher voltage amplification (ii) Higher capital cost.

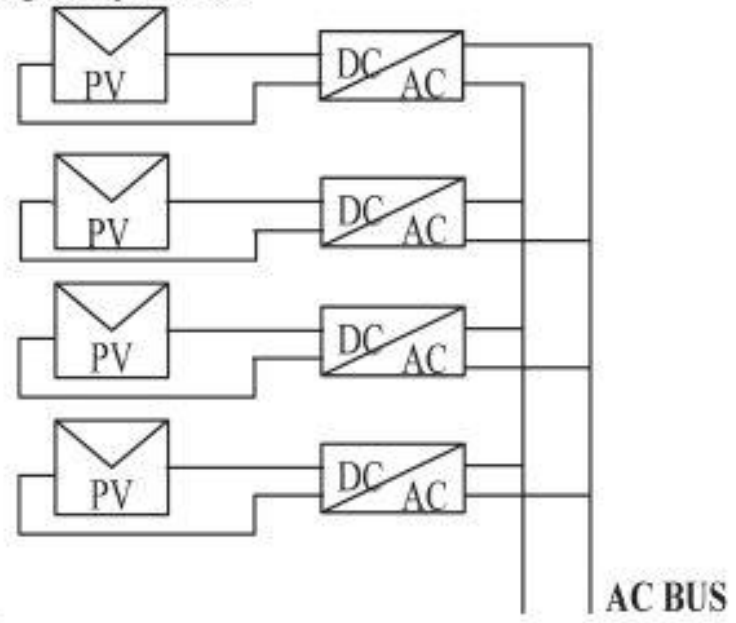

Figure 3. Module integrated inverter

Multi String Inverter: This inverter is developed in 2005. It combines the advantages of string inverters and module inverters. Each String is made of several solar panels is coupled to its own DC-DC converter with individual MPPT and feed energy to common dc to ac inverter shown in Fig. 4 [2]. The advantages of the topology are low cost, flexibility and high energy [14].

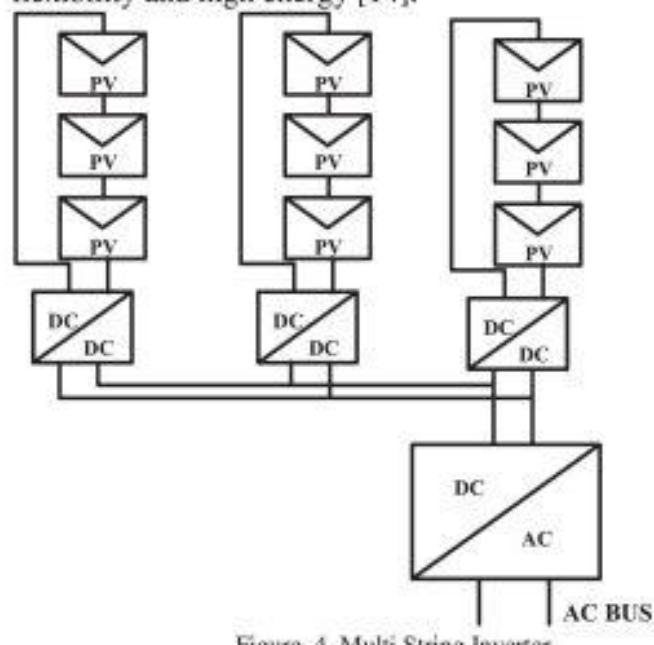

Figure 4. Multi String Inverter

\section{GRID CONNECTED INVERTERS}

The DC voltage generated from PV panels has to be converted into AC voltage of required magnitude and frequency. A typical PV system consists of PV panels, DCDC converter, DC-AC converter and a line frequency transformer on $\mathrm{AC}$ side or high frequency transformer on DC side. A PV topology using transformer on DC side is shown in Fig. 5 and PV topology using a transformer on ac side is shown in Fig. 6.

In high power applications, the PV systems are including a transformer to provide galvanic isolation between PV panels and the grid. This helps in reducing the common mode leakage currents and also provides safety [14].

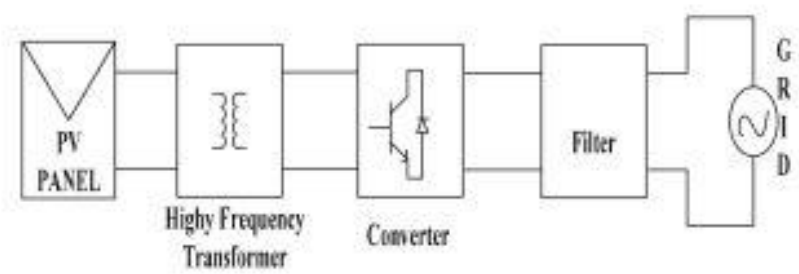

Figure 5. PV inverter topology using high frequency transformer on dc side of the converter.

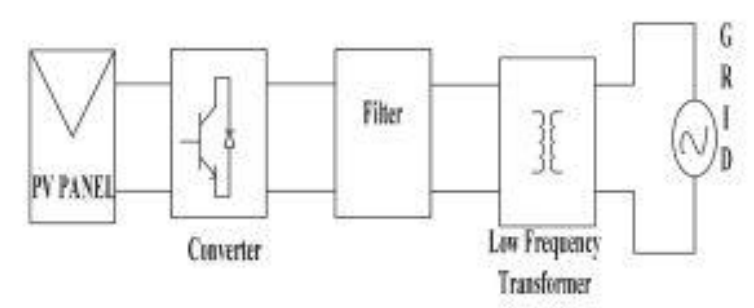

Figure 6. PV inverter topology using low frequency transformer on ac output side of the inverter

In low power domestic applications, transformer occupies large space and also reduces the efficiency of the PV system. By removing the transformer, the size of the PV system can be reduced and the efficiency can be improved. A PV transformerless topology is shown in Fig. 7.

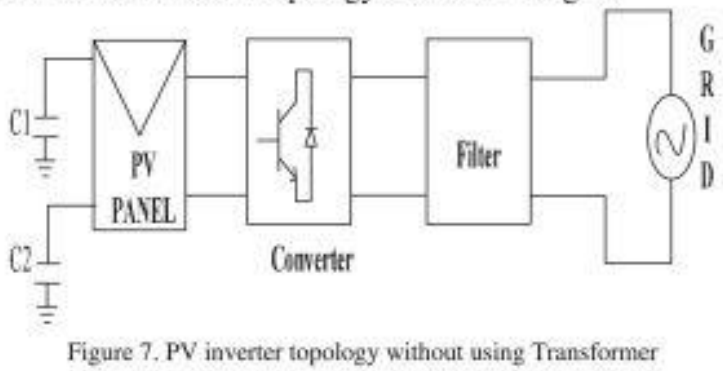

Since there is no transformer, the issues like galvanic isolation and variable common mode voltage are arisen. A variable common mode voltage results in leakage current that flows through parasitic capacitances from PV panels to the ground. This results in the increase of system losses, reduction in quality of the grid current [2].

\section{LOW POWER GRID CONNECTED INVERTER TOPOLOGIES}

In low power applications, the PV system consists of PV panels, DC-DC converter and DC-AC inverter. In single phase applications, a full bridge inverter ( $\mathrm{H} 4$ topology) shown in Fig. 8. can be used. The power semi conductor devices, IGBTs (Insulated Gate Bipolar Transistor) can be controlled using following two modulation techniques: (i) Bipolar PWM (ii) Unipolar PWM. 


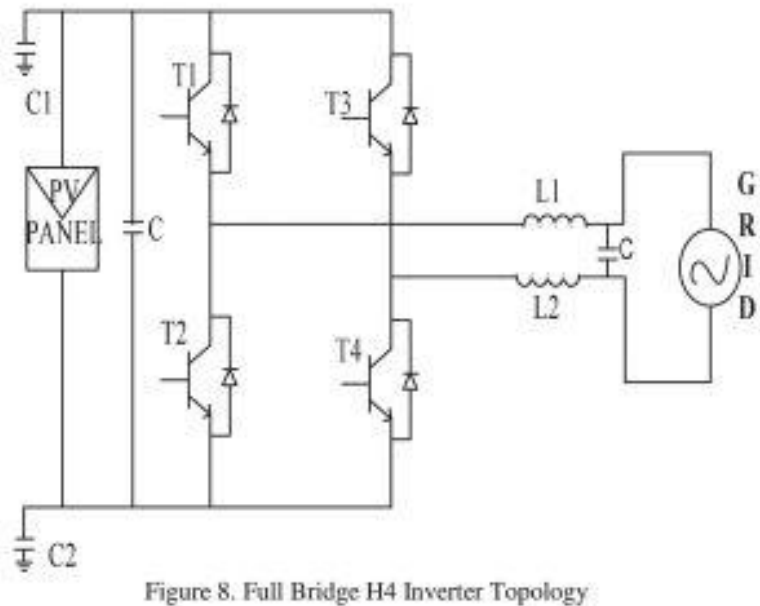

A) Bipolar PWM Techinique

In this technique, gate signals are generated by comparing a reference sinusoidal signal $V_{\text {control }}$, with a high frequency triangular waveform, $V_{\text {carrier }}$ as shown in Fig. 9. When $V_{\text {control }}>V_{\text {carrier }}$, the switches $\mathrm{T} 1$ and $\mathrm{T} 4$ are on and T2, T3 are off. When $V_{\text {cantol }}<V_{\text {carrier }}$ T2, T3 are on and T1, T4 are off. When T1, T4 are on the output voltage, $v_{o}=+V_{d c}$. When $\mathrm{T} 2, \mathrm{~T} 3$ are on the output voltage, $v_{0}=-V_{d 4}$. The output voltage oscillates between $+V_{d c}$ and $-V_{d c}$. This results in more ripple in the output current which leads to more power loss.
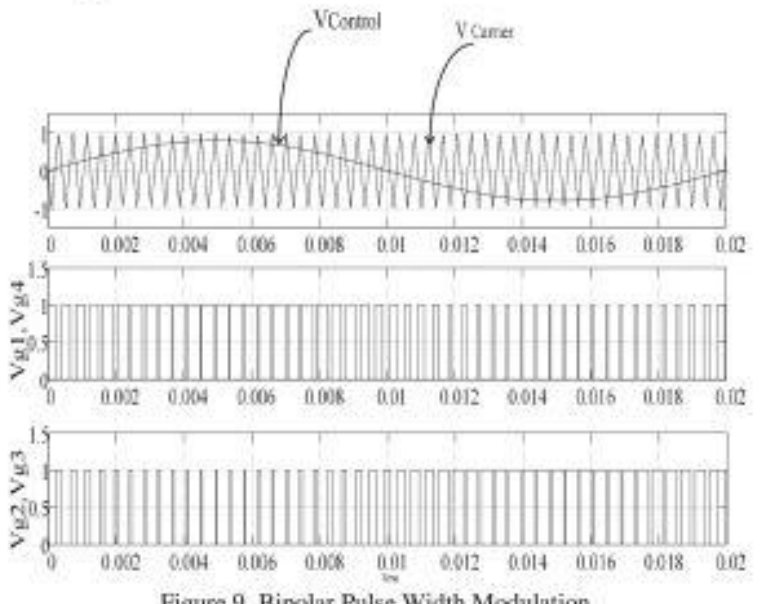

\section{A) Unipolar PWM Technique}

In this technique, the two legs of the inverter are controlled separately by using two reference sinusoidal signals, $V_{\text {comron/1 }}, V_{\text {comrow2 }}$ which are in phase opposition as shown in Fig. 10. When $V_{\text {controll }}>V_{\text {carrier }} \mathrm{T} 1$ is on and $\mathrm{T} 2$ is off. When $V_{\text {coniroil }}<V_{\text {carrier }} \mathrm{T} 1$ is off and $\mathrm{T} 2$ is on. When $V_{\text {cantrol2 } 2}>V_{\text {carrier }} \mathrm{T} 3$ is on and T4 is off. When
$V_{\text {cownoil } 2}<V_{\text {carmer }} \mathrm{T} 3$ off and $\mathrm{T} 4$ on. When $\mathrm{T} 1, \mathrm{~T} 4$ are on $v_{o}=+V_{d c}$, when T2, T3 are on $v_{o}=-V_{d c}$. When T1, T3/ T2,T4 are on $v_{o}=0$. The output voltage oscillates between $+V_{d c} 0$ and $-V_{d s}$. As there are three levels in the output voltage, the ripple in the load current is less and efficiency is more compared to bipolar PWM technique. However, this results in variable common mode voltage. To overcome this various topologies are presented in literature.
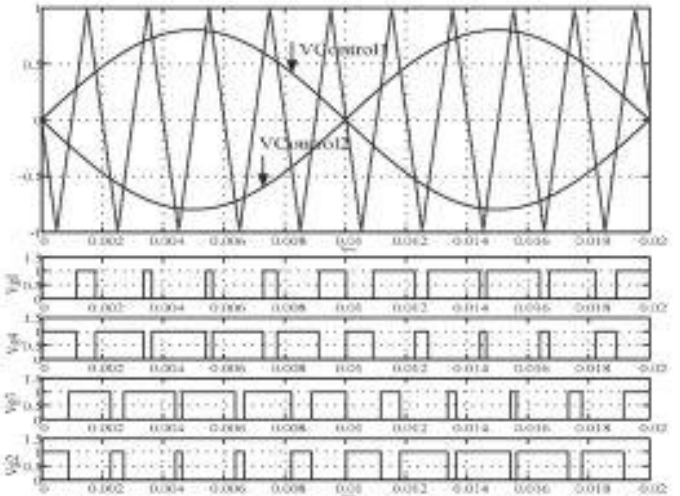

Figure 10. Unipolar Pulse Width modulation

\section{C) H5 Topology}

This topology is obtained by adding an extra switch T5 to the $\mathrm{H} 4$ topology. H5 inverter topology is modified form of $\mathrm{H} 4$ full bridge inverter by adding an extra switch T5 as shown in Fig.11. [9]. Switches T1, T3 are operated at grid frequency and switches T2, T4 are operated at switching frequency [10].

During positive half cycle T5, T4 are switched simultaneously at high frequency and T4 continuously is on. During freewheeling period T5 is off and the Current flows through $\mathrm{T} 1$ and anti parallel diode off.

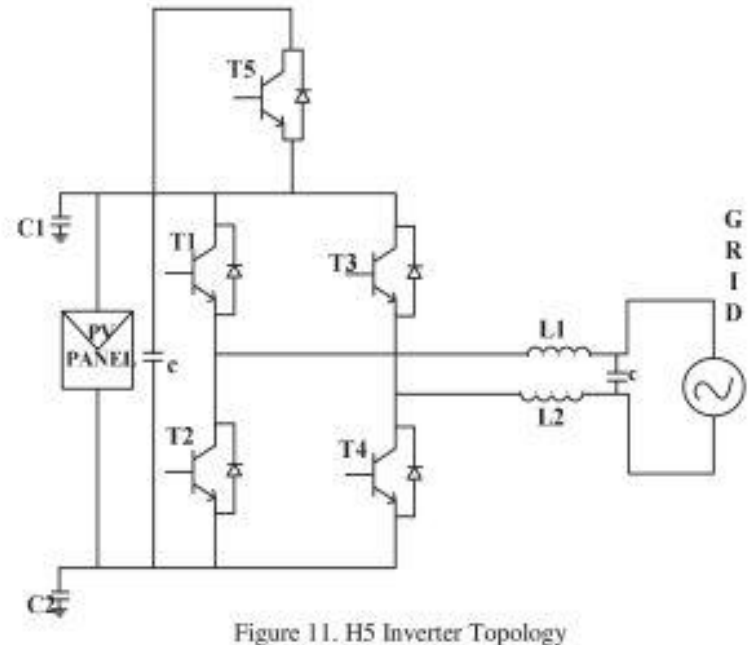

On the other hand, during, during negative half cycle $\mathrm{T} 2$, T5 are triggered at high frequency simultaneously where as T3 triggered continuously. Current flows through $\mathrm{T} 5, \mathrm{~T} 3$ and $\mathrm{T} 2$. During negative zero voltage vector T5 is 
turned off and current freewheels through T3 and anti parallel diode of T1 [7].

This topology has following disadvantages: (i) High conduction losses, as three switches are on simultaneously. (ii) Reactive power control is not possible using $\mathrm{H} 5$ topology.

\section{D) H6 Topology}

This topology is obtained by adding two additional switches T5, T6 and diodes D5, D6 as shown in Fig. 12.

During positive half cycle, T1, T4 are on continuously, T5, T6 commutated simultaneously at high frequency where as $\mathrm{T} 2, \mathrm{~T} 3$ commutate together in complement to T5 T6 pair. Hence current flows through T5, T1, T4 and T6, during positive zero voltage vectors. H6 inverter topology provides a three leveled output [7]. $\mathrm{H} 6$ topology provides constant common mode voltage thus generates very small leakage current. Hence high efficiency can be obtained.

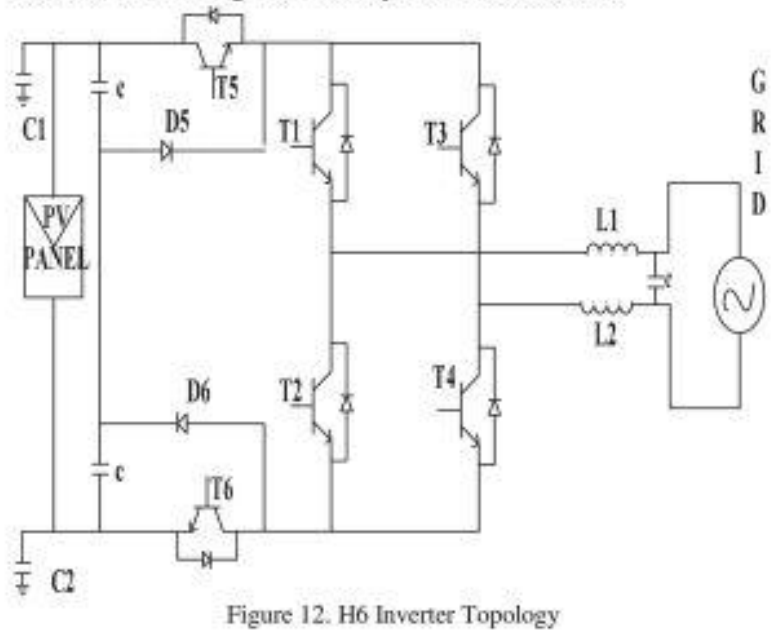

\section{E) Heric Topology}

Highly Efficient Reliable Inverter (HERIC) is obtained from $\mathrm{H} 4$ topology by adding additional switches as shown in Fig. 13. This one of the most popular transformerless inverter topology [6]. When upper switch T1 or T3 is on, voltage output will be $+V_{d c}$, when $\mathrm{T} 2$ or $\mathrm{T} 4$ is on results an output of zero. During positive half wave, T6 is turned on and is used in freewheeling period of $\mathrm{Tl}, \mathrm{T} 4$. During zero voltage vector, T1, T4 or T2, T3 are in off state. PV is disconnected from grid by short circuiting the ac side of the inverter so that this topology is predominantly ac decoupling topology [13].

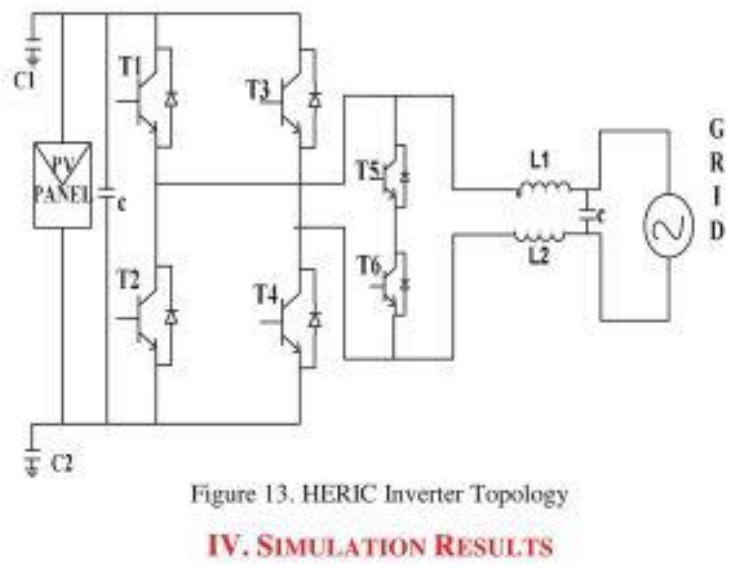

The H4 topology shown in Fig. 5 is simulated with bipolar and Unipolar PWM techniques in MATLAB SIMULINK. The simulation parameters are given in Table I.

Table I:

Simulation Parameters

\begin{tabular}{|l|l|}
\hline DC Voltage & $500 \mathrm{~V}$ \\
\hline Modulation index & 0.8 \\
\hline Fundamental frequency & $50 \mathrm{~Hz}$ \\
\hline Carrier frequency & $2.4 \mathrm{kHz}$ \\
\hline Load resistance & $10 \Omega$ \\
\hline Load inductance & $10 \mathrm{mH}$ \\
& \\
\hline
\end{tabular}

The simulation results using bipolar PWM techniques are shown in Figs. 14-16.

Fig.14. shows output voltage. From the figure, it can be seen that the output voltage oscillates between $+500 \mathrm{~V}$ and $500 \mathrm{Vas}$ discussed section III. The FFT of output voltage is shown in Fig.15. From the figure, it can be seen that the output voltage has a fundamental component of $401 \mathrm{~V}\left(\mathrm{~V}_{\mathrm{ds}}\right.$ $x$ modulation index). Moreover, it can be seen that the harmonics appear around multiples of switching frequency, $2.4 \mathrm{kHz}$. The output current is shown in Fig.16. From the current waveform it can be seen that there is significant ripple in the load current.

The simulation results using Unipolar PWM are shown in Figs, 17-19. The output voltage has three voltage levels, $+500,0$ and $-500 \mathrm{~V}$ as shown in Fig.17. From the FFT result, Fig. it can be seen that the output voltage has a fundamental component of $400.5 \mathrm{~V}$. Further it can be seen that the harmonics appear at double the switching frequency in Fig.18. From the current waveform shown in Fig.19, , it can be observed that the ripple is very less compared to that of bipolar PWM. On the other hand, during negative half cycle $\mathrm{T} 2$, T5 are triggered at high frequency simultaneously where as $\mathrm{T} 3$ triggered continuously. 


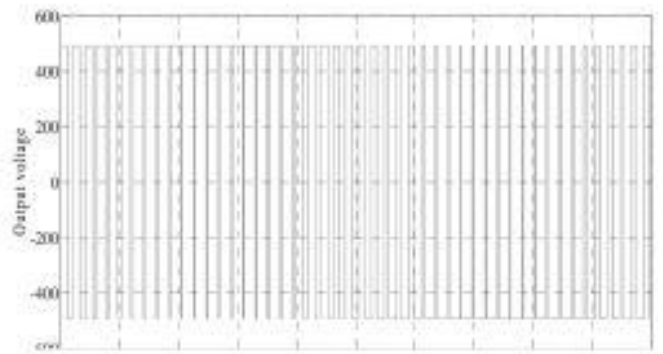

Figure 14: Output Voltage of H4 Full Bridge using Bipolar PWM of inverter topology.

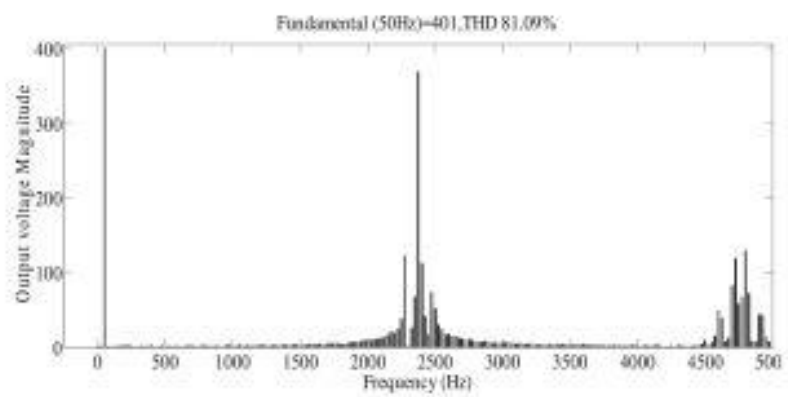

Figure 15. FFT analysis of Output voltage using bipolar PWM

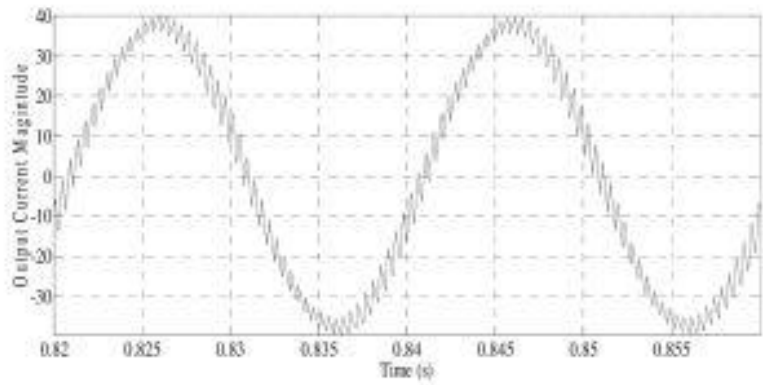

Fig. 16. Output curreet of $\mathrm{H} 4$ bridge using bipolar PWM

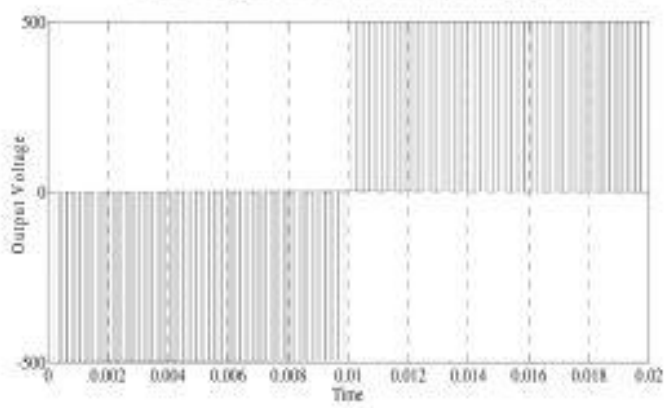

Figure 17; Output Voltage of H4 Full Bridge using unipolar PWM of inverter topology.

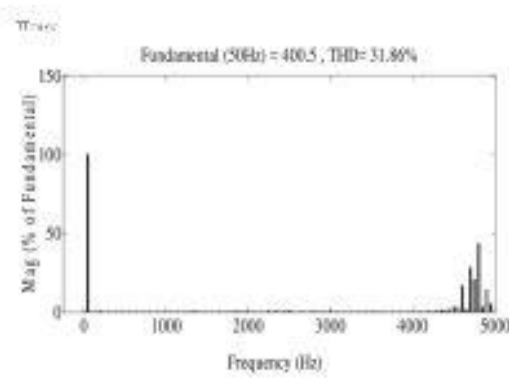

Figure 18. FFT analysis of Output voltage using unipolar PWM

It is evident that, from the Fig.16 and Fig.17, the ripple using bipolar PWM is more when compared to the ripple using unipolar PWM. Thus Unipolar PWM considered as efficient in terms of ripple component and efficiency.

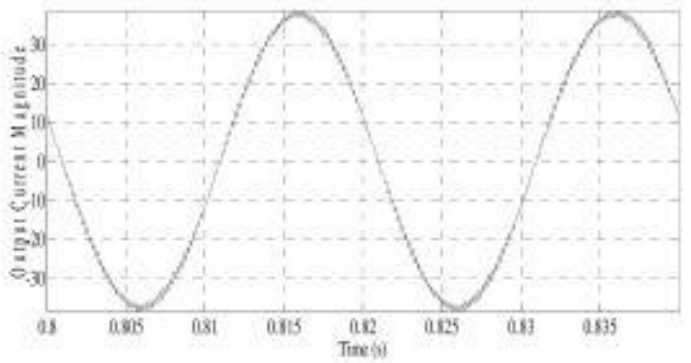

Figure 19. Output Current of H4 bridge inverter using Unipolar PWM

\section{Conclusions}

The solar power gained significant momentum in the last two decades due to advances in PV panel and power semi conductor technologies. This paper studies various topologies used in photovoltaic systems. The work aims at transformerless topologies for low power domestic applications. Various popular topologies are discussed in detail. The $\mathrm{H} 4$ topology is simulated using bipolar and Unipolar PWM techniques. From the simulation results it is concluded that Unipolar PWM technique results in (i) Less ripple in the load current. (ii) Better Total harmonic distortion compared to bipolar PWM technique. 


\section{REEERENCES}

[1] M. Islam, S. Mekheilf, "Efficient Transformerless MOSFET Inverter for Grid-Tied photovoltaic systems" IEEE Trans., Power Electron., vol.31, no.9, pp..6305-6316, Nov, 2015.

[2] T. Kerkes, Teodoreescu and M. Liserre, "Common Mode Voltage in case of Transformerless PV Inverters Connected to the Grid", IEEE Inter. Symp Ind.Electron.. pp. 2390-2395, June.2008

[3] R. Gonzalez, E. Gubia, J. Lopez, and L. Marroyo "Tranformerless single-phase multilevel-based photovoltaic inverter," IEEE Trans. Ind. Electrons, vol. 55, no. 7, pp. 2694-2702, July 2008.

[4] R. Gonzalez, J. Lopez, P. Sanchis, and L. Marroyo, "Transformerless inverter for single-phase photovoltaic systems," IEEE Trans. Power Electron., vol. 22 , no. 2, pp. 693-697, Mar. 2007.

[5] H. Xiao, S. Xie, Y. Chen, and R. Huang, "An optimized transformerless photovoltaic gridconnected inverter," IEEE Trans. Ind. Electron., vol. 58, no. 5, pp. 1887-1895, May .2011.

[6] T. K. S. Freddy, N. A. Rahim, W. P. Hew, and H. S. Che, "Modulation techniques to reduce leakage current in three-phase transformerless $\mathrm{H} 7$ photovoltaic inverter," IEEE Trans, Ind. Electron., vol. 62 , no. 1, pp. 322-331, Jan. 2015.

[7] H. F. Xiao, S. J. Xie, C. Yang, and R. H. Huang, "An optimized transformerless photovoltaic gridconnected inverter," IEEE Trans., Ind. Electron., vol. 58 , no. 5, pp. 1887-1895, May. 2011
[8] Yi Tang, Wenli Yao, Poh Chiang Loh, FredeBlaabjerg "Highly Reliable Transformerless Photovoltaic Inverters With Leakage Current and Pulsating Power Elimination" IEEE Trans., Ind.Electron, vol. 63, Issue: 2, Feb. 2016

[10] N.Vázquez, MarcoRosas, ClaudiaHernández, Eslí Vázquez; Francisco J. Perez-Pinal ' A New Common mode Transformerless Photovoltaic inverter" IEEE Trans. Ind. Electron., vol. 62, no.10

[11] H. Hu, S. Harb, N. Kutkut, I. Batarseh, and Z. Shen, "A review of power decoupling techniques for microinverters with three different decoupling capacitor locations in PV systems," IEEE Trans. Power Electron., vol. 28, no. 6, pp. 2711-2726, Jun. 2013.

[12] O. Lopez et al., "Eliminating ground current in a transformerless photovoltaic application," IEEE Trans. Energy Convers., vol. 25, no. 1,pp. 140-147, Mar. 2010.

[13] Nedmohan, Undeland, Robbins "Power Electronics: Converters, Applications and Design" WIELY Publications. Third Edition 2003

[14] S.B.Kajear, J.K.Pedersen, F.Blaaberg,"A Review of Single-Phase Grid-Connected Inverters for Photovoltaic Modules" IEEE Trans.Ind.Applics., vol.42.no.5, pp1292-1306

[15] S. V. Araujo, P. Zacharias, and R. Mallwitz, "Highly efficient single-phase transformerless inverters for grid-connected photovoltaic systems," IEEE Trans. Ind. Electron., vol. 57, no. 9, pp. 3118-3128, Sep. 2010 